\title{
PEMODELAN SISTEM INFORMASI AKSESIBILITAS DAN FILTERISASI DATA PERGURUAN TINGGI BERBASIS WEBGIS
}

\author{
Regiolina Hayami ${ }^{1}$, Mitra Unik ${ }^{2}$, Sandy Eka Nuggroho ${ }^{3}$ \\ ${ }^{123}$ Fakultas Ilmu Komputer, Universitas Muhammadiyah Riau \\ 1' regiolinahayami@umri.ac.id, ${ }^{2}$ mitraunik@umri.ac.id, ${ }^{3}$ sandyeka@student.umri.ac.id
}

\begin{abstract}
In order to obtain information related to a university through the use of the internet, the community will usually visit one by one the website pages of the relevant university, Forlap DIKTI and BAN-PT to find out the accreditation status of the chosen study program. According to statistical data from Kemenristekdikti, Pekanbaru has 46 colleges spread into 4 categories, namely Universities, Colleges, Academy, and Polytechnics. With the high number of universities spread, coupled with the many types of study programs at a tertiary institution give rise to a new problem, where the public, especially students who want to continue their education to tertiary education, are still finding it difficult to find out about information \& characteristics of a number of tertiary institutions in order to determine the chosen tertiary institution. Therefore, information system modeling is needed specifically to discuss detailed data from tertiary institutions that are equipped with an integrated filtering of the desired data from various tertiary institutions in the form of responsive web. The generated information system of university data provides 3 search filters, namely search by college name, search by type of study program, and search by closest location. The system built is integrated with digital maps to find out the location and distance of universities with users using the Google Maps API so it can be accessed mobile.
\end{abstract}

Keywords: Information system models, college data, responsive web, Google Maps API

\begin{abstract}
Abstrak
Guna mendapatkan informasi terkait suatu Perguruan Tinggi melalui penggunaan internet biasanya masyarakat akan mengunjungi satu persatu halaman website dari Perguruan Tinggi bersangkutan, Forlap DIKTI dan juga BAN-PT untuk mengetahui status Akreditasi dari Program Studi yang dipilih. Menurut data statistik dari Kemenristekdikti, kota Pekanbaru memiliki 46 perguruan tinggi yang tersebar menjadi 4 kategori, yaitu Universitas, Sekolah Tinggi, Akademi, dan Politeknik. Dengan jumlah persebaran perguruan tinggi yang cukup banyak, ditambah lagi dengan banyaknya jenis program studi pada suatu perguruan tinggi menimbulkan permasalahan baru, dimana masyarakat terutama kalangan siswa yang ingin melanjutkan pendidikan ke jenjang pendidikan tinggi dirasa masih kesulitan dalam mencari tahu tentang informasi \& karakteristik sejumlah perguruan tinggi guna menentukan perguruan tinggi pilihan. Oleh karena itu, diperlukan pemodelan sistem informasi yang dikhususkan untuk membahas tentang data detail dari perguruan tinggi yang dilengkapi dengan filterisasi pilihan terhadap data yang diinginkan secara terpadu dari berbagai perguruan tinggi dalam bentuk web responsive. Sistem informasi data perguruan tinggi yang dihasilkan menyediakan 3 filter pencarian, yaitu pencarian berdasarkan nama perguruan tinggi, pencarian berdasarkan jenis program studi, dan pencarian berdasarkan lokasi terdekat. Sistem yang dibangun diintegrasikan dengan peta digital untuk mengetahui lokasi dan jarak perguruan tinggi dengan pengguna menggunakan Google Maps API sehingga dapat diakses secara mobile.
\end{abstract}

Kata Kunci: Model sistem informasi, data perguruan tinggi, web responsive, Google Maps API

\section{PENDAHULUAN}

Perguruan tinggi merupakan tempat untuk menyelenggarakan pendidikan tinggi dan penelitian serta pengabdian kepada masyarakat. Perguruan tinggi dapat berbentuk akademi, sekolah tinggi, politeknik, institut atau universitas[1]. Dalam mencari informasi terkait suatu perguruan tinggi melalui penggunaan internet biasanya masyarakat akan mengunjungi satu persatu halaman website dari perguruan tinggi tersebut guna mendapatkan informasi yang diinginkan. Selain itu, kalangan lainnya dalam masyarakat juga mencari informasi perguruan tinggi yang diinginkan melalui halaman website 
Forlap DIKTI dan juga BAN-PT untuk mengetahui status Akreditasi dari perguruan tinggi dan program studinya.

Kota Pekanbaru merupakan ibukota dari Provinsi Riau dengan luas wilayah kurang lebih $632,3 \mathrm{~km}^{2}$, dengan letaknya yang strategis tepat berada di tengah, membuat kota Pekanbaru menjadi titik pusat dan tempat persebaran Perguruan Tinggi bagi masyarakat Provinsi Riau khususnya. Berdasarkan data dari Kementerian Riset Teknologi dan Pendidikan Tinggi(Kemenristekdikti), kota Pekanbaru memiliki 353 program studi yang tersebar pada 46 perguruan tinggi[2]. Total jumlah perguruan tinggi tersebut tentunya akan mempunyai karakterstik yang berbeda-beda, dimana jumlahnya akan semakin meningkat seiring dengan pertambahan jumlah penduduk dan perkembangan wilayah kota. Namun dengan jumlah persebaran perguruan Ttnggi yang cukup banyak, ditambah lagi dengan banyaknya jenis program studi pada suatu perguruan tinggi dalam suatu wilayah/kota, menyebabkan keterbatasan aksesibilitas data.

Indikator dari keterbatasan tersebut adalah kurang efisiennya proses yang harus dilalui pengguna untuk memperoleh data yang dibutuhkan secara terpisah-pisah. Begitu juga halnya dalam melakukan filterisasi pilihan data yang hanya berfokus pada satu nama perguruan tinggi saja menimbulkan permasalahan baru, dimana masyarakat terutama kalangan siswa masih kesulitan dalam mencari tahu tentang informasi \& karakteristik sejumlah perguruan tinggi sekaligus. Misalnya, informasi berkaitan dengan status akreditasi, jenis program studi, serta lokasi dan jarak antar perguruan tinggi dengan pengguna belum dapat diperoleh tanpa melakukan pengulangan/penggantian dalam satu waktu.

Oleh sebab permasalahan tersebut, dilakukan sebuah penelitian dengan tujuan mempermudah dalam melakukan pencarian informasi perguruan tinggi serta terintegrasi dengan letak geografis perguruan, yang kemudian akan diimplementasikan kedalam sistem Peta Digital berbasis Web, menggunakan konsep pencarian informasi perguruan tinggi dalam satu sistem serta dapat diakses dimana saja.

Sistem merupakan kumpulan komponenkomponen yang saling bekerja sama/ berhubungan satu sama lain yang memiliki aturan tertentu untuk mencapai tujuan tertentu. Informasi merupakan data yang telah diolah dan terorganisir sehingga memberikan arti dan nilai guna bagi penerimanya[3,4]. Sehingga Sistem Informasi dapat diartikan sebagai alat untuk menyajikan informasi dengan cara yang sedemikian rupa sehingga dapat bermanfaat bagi penerimanya[5]. Dalam proses pengembangan sistem tidak jarang muncul keraguan mengenai efektifitas, efisiensi dan kualitas algoritma yang sedang dikembangkan, kemampuan adaptasi sistem terhadap sistem operasinya maupun tampilannya[6]. Untuk memilimalisir keraguan tersebut hendaknya dilakukan pemodelan sistem. Dengan pemodelan sistem dapat digambarkan proses atau aktivitas dan analisa data agar dapat mendukung proses bisnis/organisasi[7].

Sistem yang akan dibangun pada penelitian ini merupakan sistem berbasis web yang dapat diakses baik melalui berbagai perangkat yang mendukung web service. Dengan sistem berbasis web, halaman yang tampil di layar web browser dapat bersifat dinamis, tergantung dari nilai data atau parameter yang dimasukan oleh user[8]. Agar tampilan sistem dapat disesuaikan dengan perangkat yang digunakan, misalkan desktop, tablet, atau mobile, maka digunakan Framework CSS Bootstrap yang akan memanggil file Bootstrap pada dokumen HTML. $[9,10]$

Pada penelitian ini sistem yang dibangun juga diterapkan metode pencarian lokasi antara pengguna dan perguruan tinggi yang dicari. Metode tersebut dikenal dengan istilah Location Based Services $(L B S)$ atau layanan pengaksesan koordinat pengguna melalui jaringan internet, yang gunanya agar pengguna dapat melakukan pencarian sekaligus mengetahui letak lokasi perguruan tinggi yang dicari serta dapat jarak dan juga petunjuk ke lokasi perguruan tinggi. Google menyediakan Google Maps API yang memungkinkan kita membangun aplikasi dengan memanfaatkan Google Maps. Dengan menggunakan peta Google dalam aplikasi yang dibangun memungkinkan memodifikasi peta dan informasi yang ada di dalamnya.[11]

\section{METODE PENELITIAN}

Dalam menyelesaikan penelitian ini akan dilalui beberapa tahapan hingga akhirnya menghasilkan suatu teknologi baru yang diharapkan dapat membantu menyelesaikan permasalahan yang dipilih. Metodologi dalam pengembangan sistem yang digunakan adalah waterfall model Adapun tahapan tersebut dapat digambarkan pada gambar 1 berikut: 


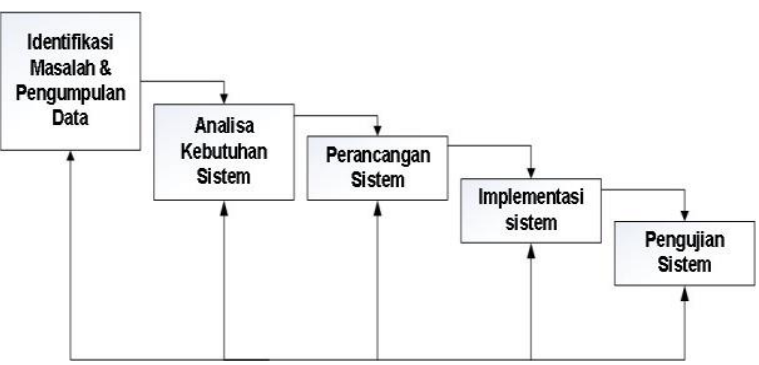

Gambar 1. Kerangka Kerja Penelitian

Berikut ini penjelasan masing-masing tahapan penelitian:

1. Identifikasi Masalah dan Pengumpulan Data

Tahap ini ditujukan untuk mendengidentifikasi permasalahan yang terjadi serta, melakukan pengumpulan datadata yang sesuai dengai permasalahan, guna membuat rancangan dalam penyelesaian permasalahan.

2. Analisa Kebutuhan Sistem

Tahapan selanjutnya dari pemodelan sistem dengan menggunakan metode waterfall model pada penelitian ini adalah melakukan identifikasi seluruh kebutuhan sistem yang akan dirancang dan diimplementasikan, antara lain :

a. Memilih metode pengembangan sistem yang akan digunakan dalam membuat perancangan sistem

b. Memilih bahasa pemrograman yang akan digunakan dalam tahapan development (pengkodean) sistem

c. Merencanakan hardware (perangkat keras) dan software (perangkat lunak) yang akan digunakan dalam melakukan penelitian tersebut.

3. Perancangan Sistem

Pada tahap ini dilakukan perancangan sesuai dengan metode pengembangan sistem yang teah ditentukan pada tahap sebelumnya. Peracangan sistem terbagi menjadi 3(tiga), yaitu perancangan Diagram Aliran Data(DAD), perancancangan Diagram Entitas, dan perancangan tampilan/ interface sistem.

4. Implementasi Sistem
Tahapan selanjutnya adalah mengimplementasikan perancangan sistem pada langkah 4. Pada Impementasi atau pengembangan sistem, akan dilakukan proses sebagai berikut:

a. Implementasi perancangan sesuai identifikasi kebutuhan sistem

b. Penulisan program dari sisi front dan back sesuai kebutuhan sistem

c. Implementasi struktur database sistem

d. Implementasi Google Maps API pada sistem dengan bahasa pemrograman javascript untuk mendapatkan sistem peta digital yang dinamis.

5. Pengujian Sistem

Tahapan akhir dari pengembangan sistem sistem adalah adalah melakukan uji coba atau testing sistem dengan menggunakan metode pengujian blackbox testing. Pengujian sistem dilakukan guna mengecek apakah sistem tersebut telah sesuai dengan yang diharapkan, serta apakah semua fungsi pada sistem telah dapat berfungsi sebagaimana mestinya.

\section{HASIL DAN PEMBAHASAN}

\section{ANALISA SISTEM}

Sistem Informasi Perguruan Tinggi(SIPT) merupakan usulan sistem yang ditawarkan guna menjawab kekurangan yang terdapat pada sistem yang berjalan saat ini. Sistem akan difokuskan pada keterpaduan antara data detil perguruan tinggi yang terintegrasi dengan Google Maps API dalam suatu sistem untuk mengetahui letak geografis/ posisi dari perguruan tinggi yang menjadi pilihan dengan lokasi pengguna. Melalui sebuah sistem yang memiliki tambang data dari berbagai situs resmi terkait perguruan tinggi dilengkapi dengan filter pencarian yang terintegrasi dengan Google Maps API, dimana pencariannya dapat dilakukan dengan berbagai media yang terkoneksi dengan internet karena pada sistem telah menggunakan metode responsive web design, diharapkan dapat mempermudah pengguna dalam memperoleh informasi perguruan tinggi yang diinginkan, khususnya di kota Pekanbaru. Pada Gambar 2 berikut adalah flowchart dari sistem yang dibangun, 


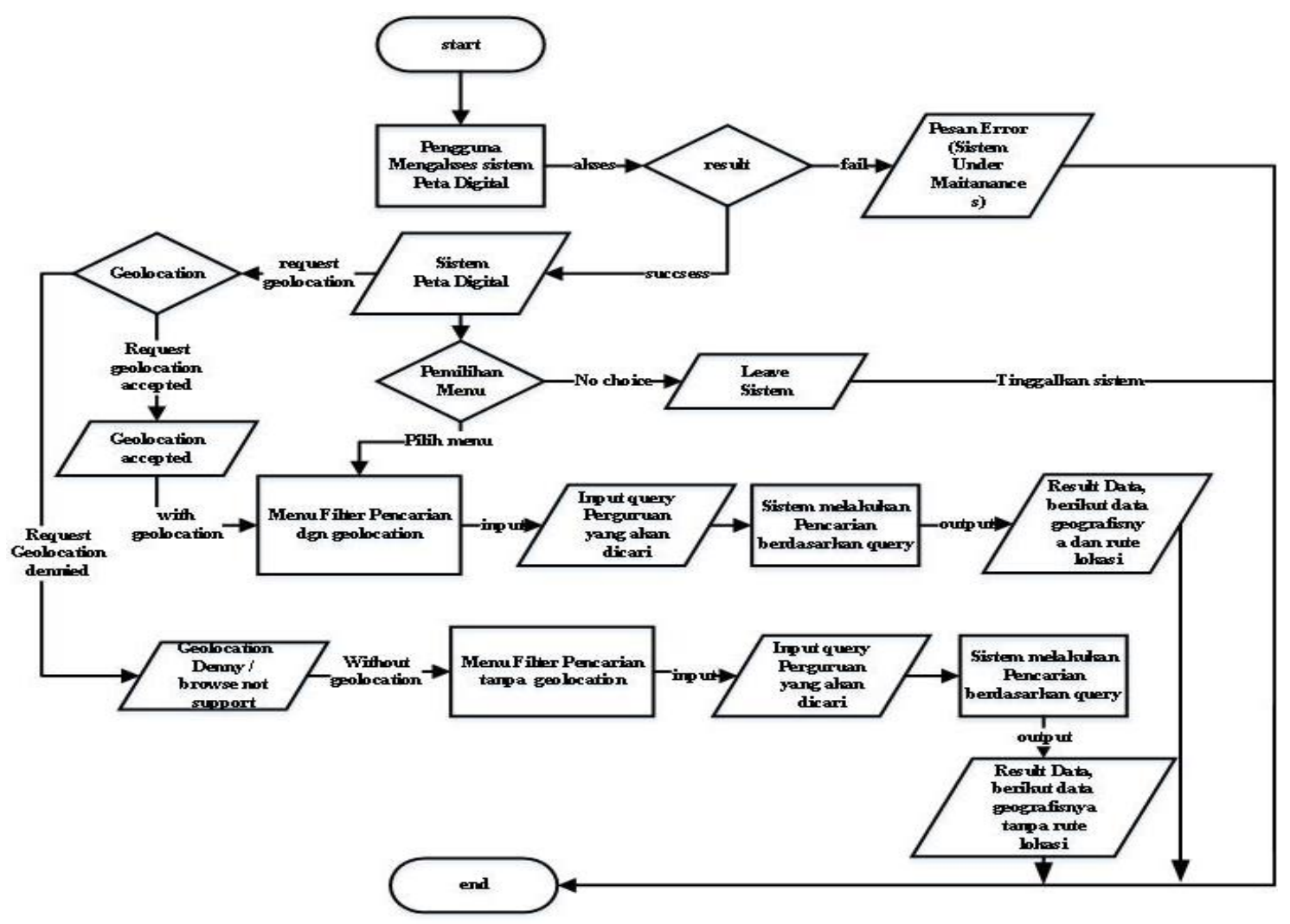

Gambar 2. Flowchart Sistem yang Dibangun

Penjelasan dari rancangan sistem yang baru, dijabarkan sebagai berikut :

1. User mengakses sistem SIPT melalui perangkat yang telah terkoneksi dengan internet

2. Kemudian secara default sistem akan meminta request akses geolocation, yang apabila akses geolocation diterima maka result pencarian dilengkapi dengan marker beserta keterangan geolocation, dan pada hasil akhir user dapat mengetahui rute menuju lokasi.

3. Apabila akses geolocation ditolak maka sistem hanya memunculkan result pencarian tanpa keterengan geolocation dan tanpa akses rute menuju lokasi.

4. Adapun fungsi filter pencarian pada sistem terdiri dari beberapa filter yaitu : a. Pencarian berdasarkan menu autocomplete nama perguruan tinggi

b. Pencarian berdasarkan filter perguruan tinggi

c. Pencarian berdasarkan filter program studi

d. Pencarian berdasarkan letak terdekat dengan pengguna yang ditentukan dengan ketentuan jarak.

Adapun data perguruan tinggi yang digunakan dalam penelitian ini terdiri dari 2(dua) jenis, yaitu data detil perguruan tinggi dan data koordinat lokasi perguruan tinggi sebagai inputan titik lokasi pada Google Maps API disistem yang dibangun. Data yang digunakan bersumber data website Forlap Dikti, Ban-PT dan titik koordinat pada Google Maps API. Tabel 1 berikut merupakan sampel data masukan sistem

Tabel 1. Data Sampel Perguruan Tinggi Kota Pekanbaru

\begin{tabular}{|c|c|c|c|c|c|c|c|}
\hline $\begin{array}{l}\mathbf{N} \\
\mathbf{o}\end{array}$ & $\begin{array}{c}\text { Nama } \\
\text { P. Tinggi }\end{array}$ & $\begin{array}{l}\text { Kate } \\
\text { gori }\end{array}$ & $\begin{array}{c}\text { Jenis } \\
\text { P. Tinggi }\end{array}$ & $\begin{array}{l}\text { Akreditasi } \\
\text { P. Tinggi }\end{array}$ & Prog. Studi & $\begin{array}{l}\text { Latti } \\
\text { tude }\end{array}$ & $\begin{array}{c}\text { Longi } \\
\text { tude }\end{array}$ \\
\hline 1 & $\begin{array}{l}\text { Universitas } \\
\text { Riau (kampus } \\
\text { 1) }\end{array}$ & $\begin{array}{l}\text { Univers } \\
\text { itas }\end{array}$ & PT. Negeri & Akreditasi A & $\begin{array}{l}\text { Ilmu Kelautan } \\
\text { Ilmu Ekonomi } \\
\text { Pendidikan Biologi } \\
\text { Ekonomi Pembangunan }\end{array}$ & $\begin{array}{l}0,47651 \\
2\end{array}$ & $\begin{array}{l}101,38 \\
0652\end{array}$ \\
\hline
\end{tabular}




\begin{tabular}{|c|c|c|c|c|c|c|c|}
\hline $\begin{array}{l}\mathbf{N} \\
\mathbf{0}\end{array}$ & $\begin{array}{c}\text { Nama } \\
\text { P. Tinggi } \\
\end{array}$ & $\begin{array}{l}\text { Kate } \\
\text { gori }\end{array}$ & $\begin{array}{c}\text { Jenis } \\
\text { P. Tinggi } \\
\end{array}$ & $\begin{array}{l}\text { Akreditasi } \\
\text { P. Tinggi }\end{array}$ & Prog. Studi & $\begin{array}{l}\text { Latti } \\
\text { tude }\end{array}$ & $\begin{array}{l}\text { Longi } \\
\text { tude }\end{array}$ \\
\hline & & & & & $\begin{array}{l}\text { Pendidikan Guru } \\
\text { Sekolah Dasar }\end{array}$ & & \\
\hline 2 & $\begin{array}{l}\text { Universitas } \\
\text { Muhammadiy } \\
\text { ah Riau } \\
\text { (Kampus } \\
\text { Utama) }\end{array}$ & $\begin{array}{l}\text { Univers } \\
\text { itas }\end{array}$ & PT. Swasta & Akreditasi B & $\begin{array}{l}\text { Teknik Infromatika } \\
\text { Sistem Informasi } \\
\text { Akuntansi } \\
\text { Fisika } \\
\text { Ilmu Hukum }\end{array}$ & $\begin{array}{l}0,49923 \\
2\end{array}$ & $\begin{array}{l}101,41 \\
5473\end{array}$ \\
\hline 3 & $\begin{array}{l}\text { Universitas } \\
\text { Islam Riau }\end{array}$ & $\begin{array}{l}\text { Univers } \\
\text { itas }\end{array}$ & PT. Swasta & Akreditasi B & $\begin{array}{l}\text { Agronomi } \\
\text { Ilmu Hukum } \\
\text { Teknik Sipil } \\
\text { Ilmu Komunikasi } \\
\text { Pendidikan Biologi }\end{array}$ & $\begin{array}{l}0,44818 \\
2\end{array}$ & $\begin{array}{l}101,45 \\
2147\end{array}$ \\
\hline 4 & $\begin{array}{l}\text { Universitas } \\
\text { Lancang } \\
\text { Kuning }\end{array}$ & $\begin{array}{l}\text { Univers } \\
\text { itas }\end{array}$ & PT. Swasta & Akreditasi B & $\begin{array}{l}\text { Ilmu Hukum } \\
\text { Agribisnis } \\
\text { Ilmu Adm. Negara } \\
\text { Sastra Indonesia } \\
\text { Sistem Informasi }\end{array}$ & $\begin{array}{l}0,57612 \\
7\end{array}$ & $\begin{array}{l}101,42 \\
4996\end{array}$ \\
\hline 5 & $\begin{array}{l}\text { Universitas } \\
\text { Islam Negeri } \\
\text { Sulthan Syarif } \\
\text { Kasim }\end{array}$ & $\begin{array}{l}\text { Univers } \\
\text { itas }\end{array}$ & PT. Negeri & Akreditasi B & $\begin{array}{l}\text { Pendidikan Agama } \\
\text { Islam } \\
\text { Hukum Keluarga } \\
\text { Psikologi } \\
\text { Teknik Informatika } \\
\text { Teknik Industri }\end{array}$ & $\begin{array}{l}0,46367 \\
3\end{array}$ & $\begin{array}{l}101,35 \\
6771\end{array}$ \\
\hline 6 & $\begin{array}{l}\text { Sekolah } \\
\text { Tinggi Ilmu } \\
\text { Ekonomi } \\
\text { Purna Graha }\end{array}$ & $\begin{array}{l}\text { Sekola } \\
\mathrm{h} \\
\text { Tinggi }\end{array}$ & PT. Swasta & Akreditasi B & $\begin{array}{l}\text { Akuntansi } \\
\text { Manajemen }\end{array}$ & $\begin{array}{l}0,50246 \\
1\end{array}$ & $\begin{array}{l}101,42 \\
3985\end{array}$ \\
\hline 7 & $\begin{array}{l}\text { STMIK Amik } \\
\text { Riau }\end{array}$ & $\begin{array}{l}\text { Sekola } \\
\mathrm{h} \\
\text { Tinggi }\end{array}$ & PT. Swasta & Akreditasi B & $\begin{array}{l}\text { Sistem Informasi } \\
\text { Teknik Informatika } \\
\text { Teknologi Informasi } \\
\text { Manajemen Informatika }\end{array}$ & $\begin{array}{l}0.4486 .0 \\
0\end{array}$ & $\begin{array}{l}101,39 \\
76602\end{array}$ \\
\hline 8 & $\begin{array}{l}\text { Sekolah } \\
\text { Tinggi Ilmu } \\
\text { Kesehatan } \\
\text { Hang Tuah }\end{array}$ & $\begin{array}{l}\text { Sekola } \\
\mathrm{h} \\
\text { Tinggi }\end{array}$ & PT. Swasta & Akreditasi B & $\begin{array}{l}\text { Ilmu Kesehatan } \\
\text { Masyarakat } \\
\text { Ilmu Keperawatan } \\
\text { Kebidanan }\end{array}$ & $\begin{array}{l}0,48323 \\
2\end{array}$ & $\begin{array}{l}101,45 \\
6981\end{array}$ \\
\hline 9 & $\begin{array}{l}\text { Sekolah } \\
\text { Tinggi Ilmu } \\
\text { Komputer } \\
\text { Pelita } \\
\text { Indonesia }\end{array}$ & $\begin{array}{l}\text { Sekola } \\
\mathrm{h} \\
\text { Tinggi }\end{array}$ & PT. Swasta & Akreditasi B & $\begin{array}{l}\text { Sistem Informasi } \\
\text { Teknik Informatika }\end{array}$ & $\begin{array}{l}0,52620 \\
6\end{array}$ & $\begin{array}{l}101,44 \\
1988\end{array}$ \\
\hline 10 & $\begin{array}{l}\text { Sekolah } \\
\text { Tinggi Bahasa } \\
\text { Asing Persada } \\
\text { Bunda }\end{array}$ & $\begin{array}{l}\text { Sekola } \\
\mathrm{h} \\
\text { Tinggi }\end{array}$ & PT. Swasta & Akreditasi C & $\begin{array}{l}\text { Sastra Inggris } \\
\text { Bahasa Inggris }\end{array}$ & $\begin{array}{l}0,51193 \\
4\end{array}$ & $\begin{array}{l}101,45 \\
1943\end{array}$ \\
\hline 11 & $\begin{array}{l}\text { Akademi } \\
\text { Sekretari Dan } \\
\text { Manajemen } \\
\text { Persada Bunda }\end{array}$ & $\begin{array}{l}\text { Akade } \\
\text { mi }\end{array}$ & PT. Swasta & Akreditasi C & $\begin{array}{l}\text { Manajemen Perusahaan } \\
\text { Sekretari }\end{array}$ & $\begin{array}{l}0,51193 \\
4\end{array}$ & $\begin{array}{l}101,45 \\
1943\end{array}$ \\
\hline 12 & $\begin{array}{l}\text { AMIK } \\
\text { Mahaputra } \\
\text { Riau }\end{array}$ & $\begin{array}{l}\text { Akade } \\
\text { mi }\end{array}$ & PT. Swasta & Akreditasi C & Manajemen Informatika & $\begin{array}{l}0,49315 \\
5\end{array}$ & $\begin{array}{l}101,43 \\
8161\end{array}$ \\
\hline 13 & $\begin{array}{l}\text { AMIK Tri } \\
\text { Dharma } \\
\text { Pekanbaru }\end{array}$ & $\begin{array}{l}\text { Akade } \\
\text { mi }\end{array}$ & PT. Swasta & Akreditasi C & $\begin{array}{l}\text { Manajemen Informatika } \\
\text { Teknik Komputer }\end{array}$ & $\begin{array}{l}0,53530 \\
8\end{array}$ & $\begin{array}{l}101,44 \\
7345\end{array}$ \\
\hline 14 & $\begin{array}{l}\text { Akademi } \\
\text { Kebidanan }\end{array}$ & $\begin{array}{l}\text { Akade } \\
\text { mi }\end{array}$ & PT. Swasta & Akreditasi B & Kebidanan & $\begin{array}{l}0,49982 \\
6\end{array}$ & $\begin{array}{l}101,45 \\
351\end{array}$ \\
\hline
\end{tabular}




\begin{tabular}{|c|c|c|c|c|c|c|c|}
\hline $\begin{array}{l}\mathbf{N} \\
\mathbf{0}\end{array}$ & $\begin{array}{c}\text { Nama } \\
\text { P. Tinggi }\end{array}$ & $\begin{array}{l}\text { Kate } \\
\text { gori }\end{array}$ & $\begin{array}{c}\text { Jenis } \\
\text { P. Tinggi }\end{array}$ & $\begin{array}{c}\text { Akreditasi } \\
\text { P. Tinggi }\end{array}$ & Prog. Studi & $\begin{array}{l}\text { Latti } \\
\text { tude }\end{array}$ & $\begin{array}{c}\text { Longi } \\
\text { tude }\end{array}$ \\
\hline 15 & $\begin{array}{l}\text { Internasional } \\
\text { Pekanbaru } \\
\text { Politeknik } \\
\text { Caltex }\end{array}$ & $\begin{array}{l}\text { Politek } \\
\text { nik }\end{array}$ & PT. Swasta & Akreditasi B & $\begin{array}{l}\text { Sistem Informasi } \\
\text { Teknik Elektronika } \\
\text { Teknik Informatika }\end{array}$ & $\begin{array}{l}0.57018 \\
12\end{array}$ & $\begin{array}{l}101,42 \\
33154\end{array}$ \\
\hline
\end{tabular}

\section{PERANCANGAN SISTEM}

\subsection{PERANCANGAN DFD}

Salah satu teknik perancangan yang digunakan dalam perancangan sistem pada penelitian ini adalah DFD(Data Flow Diagram). DFD merupakan suatu diagram yang berisikan aliran aliran data baik berupa data masukan maupun data keluaran dari sistem. Gambar 3 berikut merupakan DFD level 0(Context Diagram) dari sistem yang dibangun:

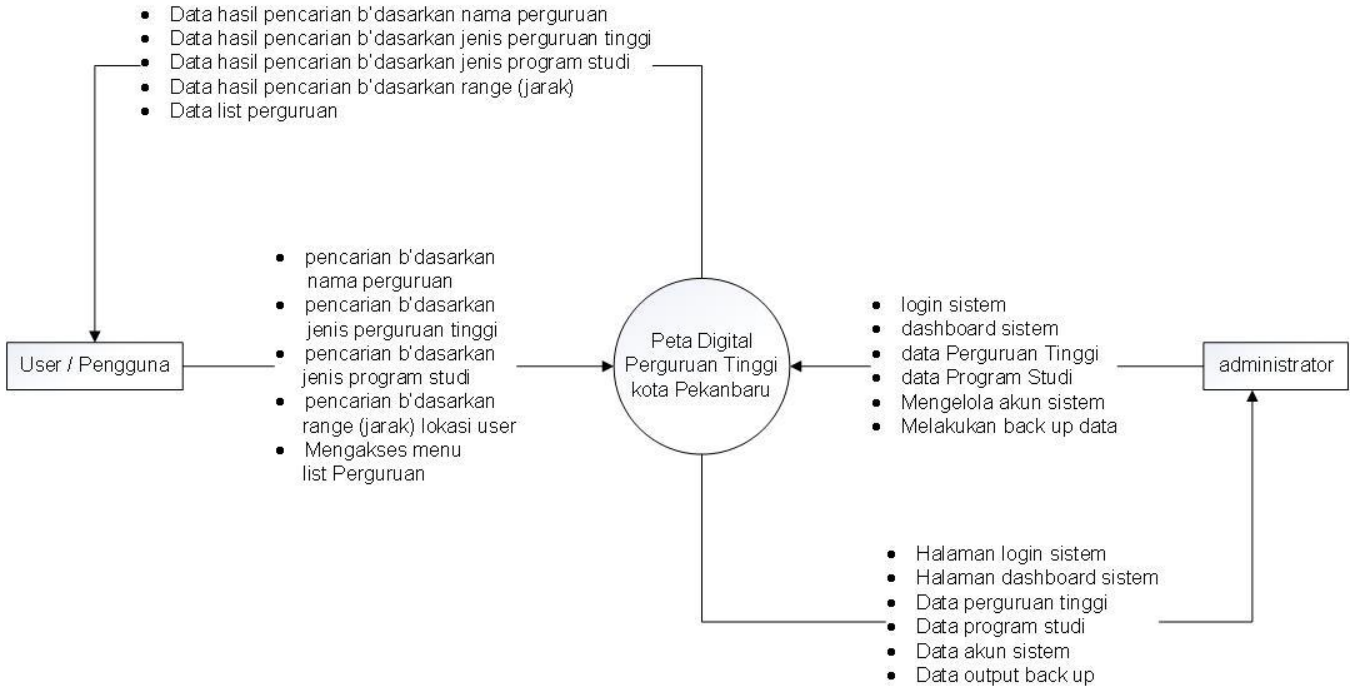

Gambar 3. Context Diagram Sistem

\subsection{PERANCANGAN BASIS DATA}

Entity

Relationship

Diagram(ERD) merupakan tools yang digunakan untuk memodelkan struktur data dengan menggambarkan entitas dan hubungan antar entitas secara abstrak atau konseptual, pada dasarnya ERD dibentuk oleh beberapa notasi yaitu Entity, Relationship, Attribute. Gambar 4 berikut ini merupakan ERD dari sistem yang dibangun,

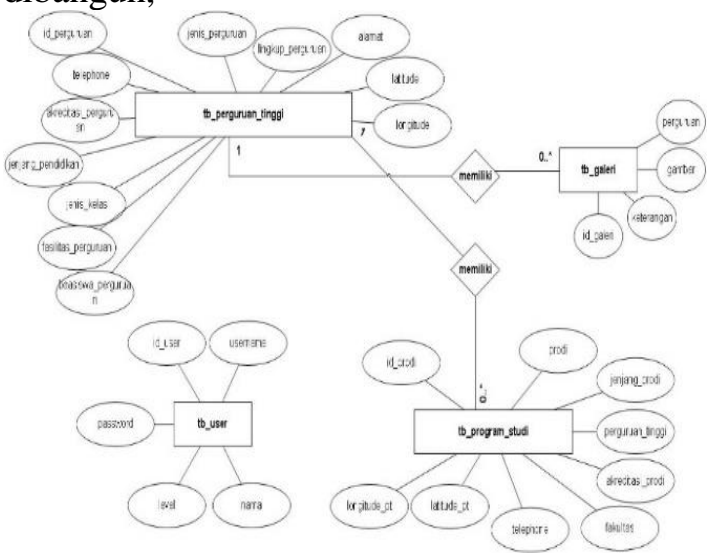

Gambar 4. ER Diagram Sistem

\subsection{PERANCANGAN SISTEM \\ WIREFRAME}

Tahap selanjutnya dalam perancangan sistem adalah perancangan wireframe/ tampilan sistem. Perancagan tampilan sistem menggambarkan halaman antar muka sistem, berfokus pada tata letak, fungsi yang terletak pada tampilan, dan alur prilaku antar muka. Gambar 5 berikut merupakan salahsatu tampilan perancangan wireframe sistem yang dibangun:

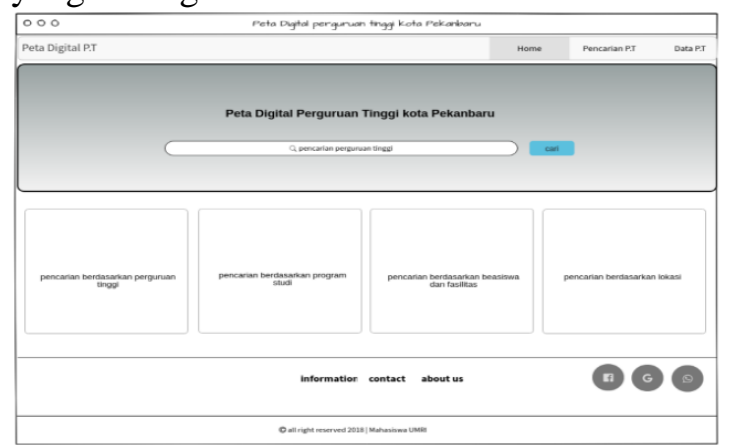

Gambar 5. wireframe dalam perancangan sistem 


\section{IMPLEMENTASI SISTEM}

Implementasi sistem dilakukan dengan menggunakan bahasa pemrograman PHP versi 5.6.15 dan database mysql 4.5.1 dengan ekstensi MySQLi, sedangkan bahasa markup yang digunakan adalah HTML5 disertakan dengan framework CSS Boostrap 4. Serta pada implementasi map menggunakan Google Maps API versi 3. Tahap implementasi merupakan tahap penulisan kode program sesuai dengan bahasa pemrograman disertai terhadap desain sistem yang telah dirancang sebelumnya.

\subsection{IMPLEMENTASI HALAMAN AWAL SISTEM}

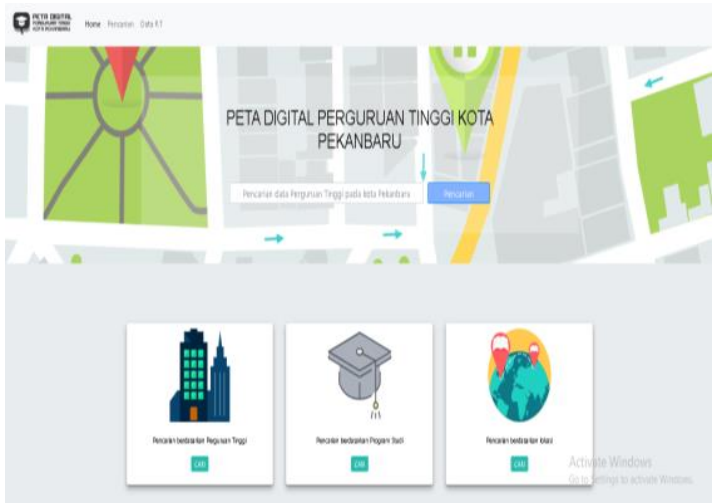

Gambar 6. implementasi halaman awal system

Gambar 6 merupakan tampilan halaman utama sistem akan tampil apabila $U R L$ dipanggil pada browser. Pada tampilan utama disediakan beberapa pilihan pencarian data perguruan tinggi, yaitu:

a. Pencarian berdasarkan nama perguruan tinggi

b. Pencarian berdasarkan jenis perguruan tinggi

c. Pencarian berdasarkan program studi

d. Pencarian berdasarkan lokasi terdekat dengan pengguna (hanya digunakan jika akses lokasi diterima)

Pada setiap menu pencarian dilengkapi dengan peta digital yang menunjukkan lokasi pada peta dan petunjuk arah menuju lokasi yang dipilih.

\subsection{IMPLEMENTASI HALAMAN PENCARIAN \\ PERGURUAN TINGGI}

Gambar 7 menggambarkan tentang tampilan hasil pada fungsi pencarian berdasarkan perguruan tinggi, yang menampilkan data perguruan sesuai dengan inputan query beserta dengan data geolocation dari pengguna.

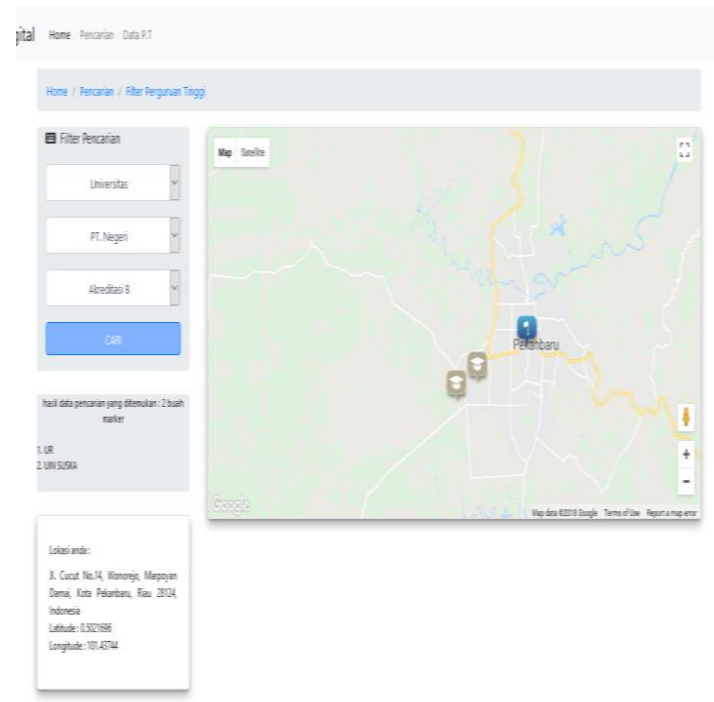

Gambar 7. Implementasi hasil pencarian data perguruan tinggi yang dilengkapi dengan data geolocation

\subsection{IMPLEMENTASI HASIL PENCARIAN DATA PERGURUAN TINGGI} BERDASARKAN LOKASI PENGGUNA

Selain dapat melakukan pencarian berdasarkan jenis perguruan tinggi, tersedia juga fitur untuk mencari perguruan tinggi terdekat dengan lokasi pengguna. Pengguna dapat menentukan batas jarak yang diingikan untuk mengetahui perguruan tinggi apa saja yang ada dalam radius jarak yang dipilih. Gambar 8 erikut adalah tampilan pencarian data berdasarkan lokasi pengguna:

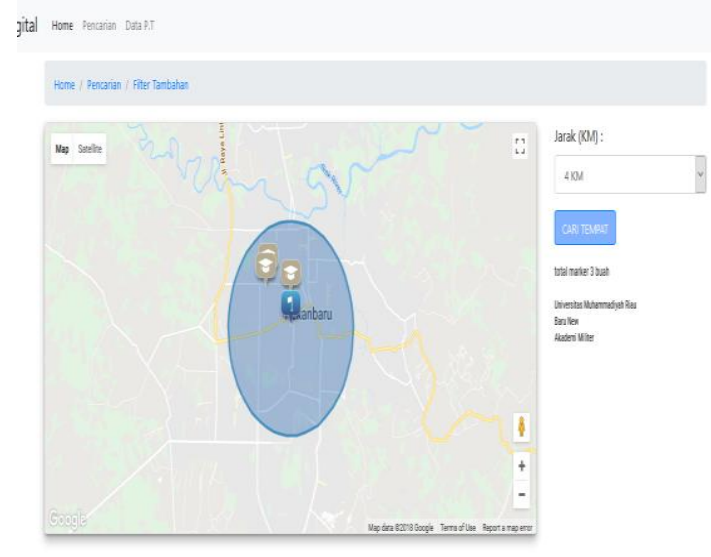

Gambar 8. Implementasi hasil pencarian data perguruan tinggi yang dilengkapi dengan data geolocation 


\subsection{IMPLEMENTASI HASIL PENCARIAN DATA PERGURUAN TINGGI}

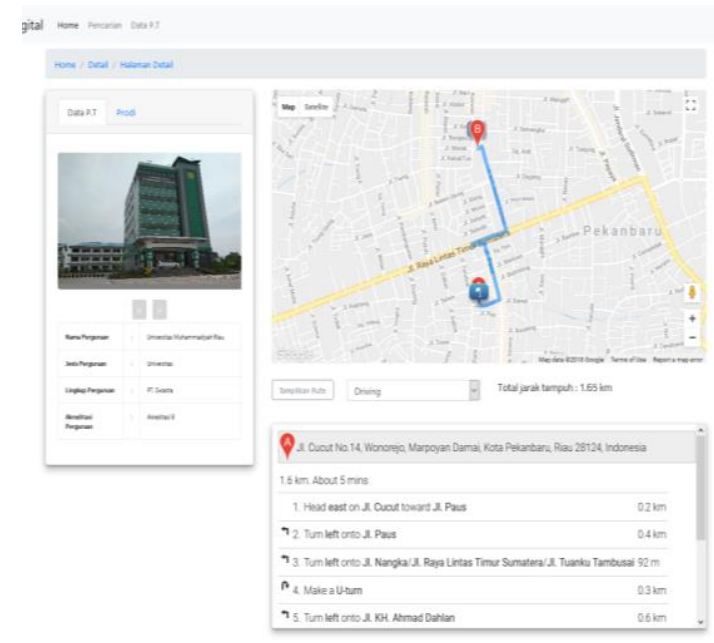

Gambar 8. implementasi hasil pencarian berupa halaman detail pada sistem

Gambar 8 menggambarkan tentang tampilan halaman rincian hasil pencarian data suatu perguruan tinggi. Pada sistem ditampilkan data yang berkaitan dengan data perguruan tinggi yang dipilih beserta dengan rute dari posisi pengguna sampai ke lokasi perguruan yang dituju. Sistem menampilkan petunjuk dan arah yang harus ditempuh pengguna agar dapat sampai ke lokasi perguruan tinggi yang dipilih, dimana metode perjalanan dapat diganti dengan menggunakan metode yang tersedia pada fungsi rute Google Maps API.

\section{PENGUJIAN SISTEM}

Pengujian atau testing merupakan elemen kritis dari jaminan kualitas perangkat lunak dan merupakan bagian yang tidak terpisah dari siklus hidup pengembangan software seperti halnya analisis, desain, dan pengkodean. Dalam tahapan pengujian sistem tersebut digunakan metode black box testing yang bertujuan untuk menemukan beberapa hal seperti, fungsi yang tidak benar atau tidak ada, kesalahan antarmuka (interfaces error), kesalahan pada struktur data dan akses basis data, kesalahan performansi (performance errors), kesalahan inisialisasi dan terminasi.

\section{SIMPULAN DAN SARAN}

Berdasarkan hasil penelitian yang telah dilakukan dengan judul peta digital berbasis web dengan memanfaatkan google maps API dan menggunakan metode location based service sebagai informasi petunjuk perguruan tinggi di kota Pekanbaru, memberikan kesimpulan yaitu :

1. Pada hasil akhir penelitian ini menghasilkan sebuah sistem yang memiliki maksud dan tujuan agar pengguna dapat lebih mudah dalam menemukan data suatu perguruan tinggi yang sesuai dengan kriteria yang diinginkan oleh pengguna.

2. Serta dengan adanya hasil penelitian ini diharapkan dapat membantu berbagai pihak dalam mengelola data-data perguruan tinggi dalam cakupan wilayahnya.

Walaupun sistem ini telah menggunakan teknologi responsive web design, namun akan lebih baik apabila sistem dapat dikembangkan menjadi aplikasi dengan teknologi berbasis Web-Mobile dengan pertukaran data, menggunakan RestFull WebServices yang dapat lebih memudahkan pengguna dalam menggunakan sistem.

\section{TERIMA KASIH}

Terima kasih kepada berbagai pihak yang terlibat dalam penelitian ini hingga tahap akhir. Selain itu ucapan terima kasih kepada Kementerian Riset, Teknologi dan Pendidikan Tinggi yang telah mendukung pendanaan dalam penelitian ini.

\section{DAFTAR PUSTAKA}

[1] E. Rchardus and Djokopranoto, Manajemen Perguruan Tinggi. 2009.

[2] teknologi dan P. T. Kementerian Riset, Buku Statistik Pendidikan Tinggi. Jakarta: Pusdatin Iptek Dikti, 2017.

[3] M. W. Turban, Leidner, information technology fo management, 6th ed. Pte Ltd, 2008.

[4] P. . Jogiyanto, H.M., MBA, "Konsep Dasar Sistem," no. 1993, pp. 8-29, 2005.

[5] F. E. Andalia and B. Setiawan, "Pengembangan Sistem Informasi Pengolahan data pencari kerja pada dinas sosial dan tenaga kerja kota padang," $J$. Ilm. Komput. dan Inform., vol. 4, no. 2, 2015.

[6] R. P. Dian, Metodologi Pengembangan sistem informasi. Fakultas Ilmu Komputer, 2013.

[7] H. Al Fatta, Analisis dan Perancangan Sistem Informasi untuk Keunggulan Bersaing Perusahaan dan Organisasi Modern. Penerbit Andi, 2007.

[8] B. Raharjo, Modul Pemrograman Web, 
3rd ed. Bandung: Modula, 2016.

[9] Bootstrap Responsive Web Design. 2014.

[10] "Bootstrap 3 tutorials." [Online]. Available:

https://www.w3schools.com/bootstrap/def ault.asp. [Accessed: 15-Apr-2019].

[11] M. Dian, "Tutorial Google Maps API: Menampilkan Peta Google Map di dalam Web." [Online]. Available: https://www.petanikode.com/google-mapdasar/. . [Accessed: 16-Apr-2019]. 